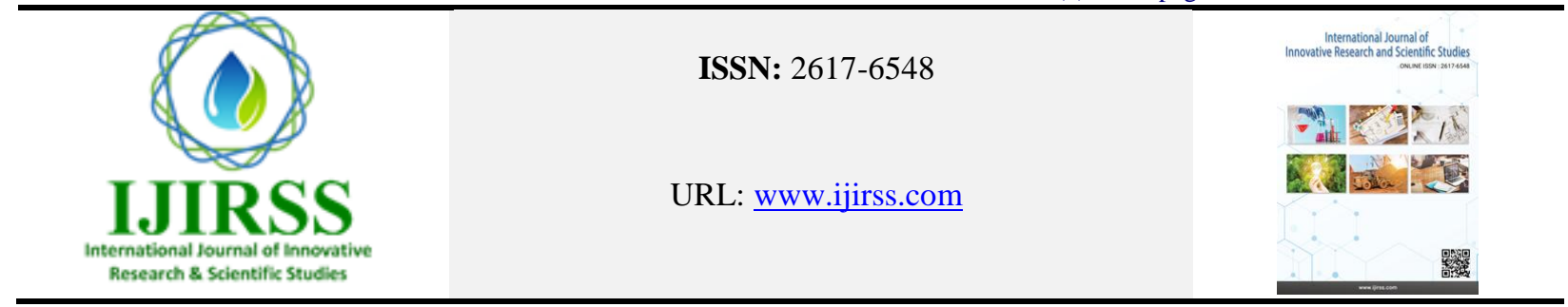

\title{
Biosurfactants as Promising Multifunctional Agent: A Mini Review
}

\author{
Sweeta Akbari ${ }^{1 *}$, Abdurahman Hamid Nour $^{2}$, Rosli Mohd Yunus ${ }^{3}$, Abdulrahman Hasan Farhan ${ }^{4}$ \\ 1,2,3,4 Faculty of Chemical \& Natural Resources Engineering, Universiti Malaysia Pahang, Lebuhraya Tun Razak, 26300 Gambang, \\ Pahang, Malaysia \\ *Corresponding author: Sweeta Akbari (sweeta.akbary11@yahoo.com)
}

\begin{abstract}
Biosurfactants are derived from plants and microorganisms such as fungi, yeast, and bacteria. Biosurfactants are also called natural surfactants which are amphiphilic biological compounds comprised of both hydrophilic and hydrophobic moieties. The environmental concerns about the effect of toxic and conventional surfactants have increased the demand for renewable and biodegradable surfactants with low toxicity and other useful effects. Therefore, the application of biosurfactants has gained much attention in different industries mainly in petroleum, food, cosmetic and pharmaceutical products. This review summarizes the utilization of biosurfactants as emulsifying, wetting, foaming and antimicrobial agents in various industrial processes along with their promising availability and ensuring environmental quality.
\end{abstract}

Keywords: Biosurfactant, HLB, Biosurfactant properties, Contact angle.

DOI: 10.53894 /ijirss.v1i1.2

Funding: This study received no specific financial support.

History: Received: 5 February 2018/Revised: 22 February 2018/Accepted: 2 March 2018/Published: 20 September 2018

Licensed: This work is licensed under a Creative Commons Attribution 4.0 License $(\mathrm{cc}) \mathrm{Er}$

Acknowledgement: All authors contributed to the conception and design of the study.

Competing Interests: The authors declare that they have no conflict of interests.

Transparency: The authors confirm that the manuscript is an honest, accurate, and transparent account of the study was reported; that no vital features of the study have been omitted; and that any discrepancies from the study as planned have been explained.

Ethical: This study follows all ethical practices during writing.

\section{Introduction}

Biosurfactants are also known as surface active bio-compounds comprised of both hydrophilic (showing affinity to polar materials) and hydrophobic (having affinity to non-polar materials). The hydrophilic part of the surfactants are composed of amino acids, carbohydrates, phosphates, cyclic peptide, alcohols or carboxylic acids. However, the hydrophobic portion, are based on the long-chain fatty acids, $\alpha$-alkyl- $\beta$ - hydroxy fatty acids or hydroxyl fatty acids [1, 2]. Currently, biosurfactants have gained much attention due to their advantages over the chemical surfactants in terms of their low toxicity, environmental capability, biodegradability, renewability, availability of natural resources, desirable functionality, and better availability for a wide range of $\mathrm{pH}$ values and temperatures [2,3]. Hence, these properties enabled them to be a promising component with a wide range of application in many industries, especially for heavy metal removal in contaminated soil [4-6], microbial enhanced oil recovery [7-10], therapeutic agent in cosmetic and pharmaceutical products $[1,11,12]$.

Biosurfactants have the same functionality as the chemical synthesized surfactants, such as lowering the surface and interfacial tension, emulsification, solubilization, foaming, dispersion, wetting, antimicrobial activity, cleansing and many other useful properties. However, in many cases biosurfactant are considered much better compared to the synthetic 
surfactants, especially in terms of environmental capability. Generally, biosurfactants are classified in two categories. Low molecular weight and high molecular weight. Low molecular weight biosurfactants have excellent surface properties due to their simple structure including glycolipids lipopeptides and phospholipids. However, high molecular weight biosurfactants are effective for emulsification and stabilization, as their major classes are polymeric and particulate biosurfactants [1, 1214]. In addition, another important characteristic of biosurfactants is hydrophilic-lipophilic balance (HLB) which specifies the value of hydrophilic and hydrophobic compounds in surface-active substances. Figure 1 shows a surfactant monomer with both hydrophilic and hydrophobic parts.
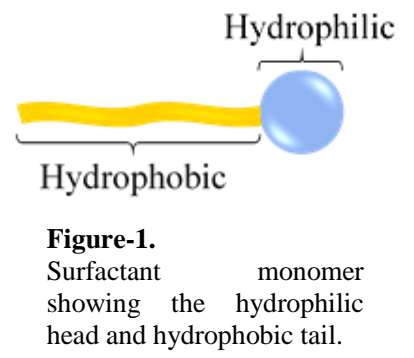

The HLB affects the stability of the emulsion. A low HLB value of the surfactant indicates a hydrophobic (containing more nonpolar groups) preferred for water-in-oil (W/O) emulsions. While, a high value of HLB (with more polar groups) forms an oil-in-water $(\mathrm{O} / \mathrm{W})$ emulsion. Table 1 indicates a summary of HLB ranges and their applications [15]. Figure 2 displays the HLB value application for $\mathrm{W} / \mathrm{O}$ and $\mathrm{O} / \mathrm{W}$ emulsions.

Table-1.

HLB numbers in range for different applications [16]

\begin{tabular}{ll}
\hline HLB Value & Application \\
\hline $3-6$ & W/O emulsifier \\
$7-9$ & Wetting agent \\
$8-18$ & O/W emulsifier \\
$12-15$ & Detergent \\
$15-18$ & Solubilizer \\
\hline
\end{tabular}

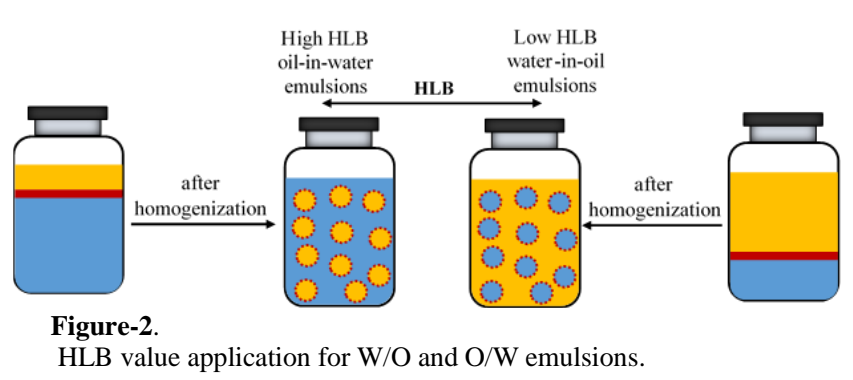

The objective of this review was to collect information about different applications of biosurfactants as emulsifying, wetting, foaming and antimicrobial agents in various industrial processes along with their promising availability and ensuring environmental quality.

\section{Physicochemical Properties of Biosurfactants}

\subsection{Emulsifying Property of Biosurfactants}

Generally, biosurfactants exhibited an excellent emulsifying activity by reducing the surface tension of water and oil. The ability of biosurfactants as emulsifying agent is related to hydrocarbon structure. Biosurfactants can stabilize many hydrocarbons such as tri-decane, tetra-decane, hexa-decane, methyl-naphtalene, heavy and light crude oil, diesel, kerosene, benzene, and many other forms of hydrocarbons [8, 13, 17]. Peele, et al. [18] tested the emulsifying activity of biosurfactant produced by marine bacterium against different hydrocarbons such as benzene, xylene, kerosene, diesel and petrol. Based on their evaluation the produced biosurfactant was able to stabilize the emulsions for more than one week. In addition, Camacho-Chab, et al. [19], found that biosurfactants can perform better than gum Arabic.

\subsection{Wetting Property of Biosurfactants}

Wetting is an essential process in which the phase of on liquid is displaced by another fluid from the surface of a solid. The wetting ability of a surfactant is described by contact angle $\theta$ of a liquid drop on a solid surface [20]. 


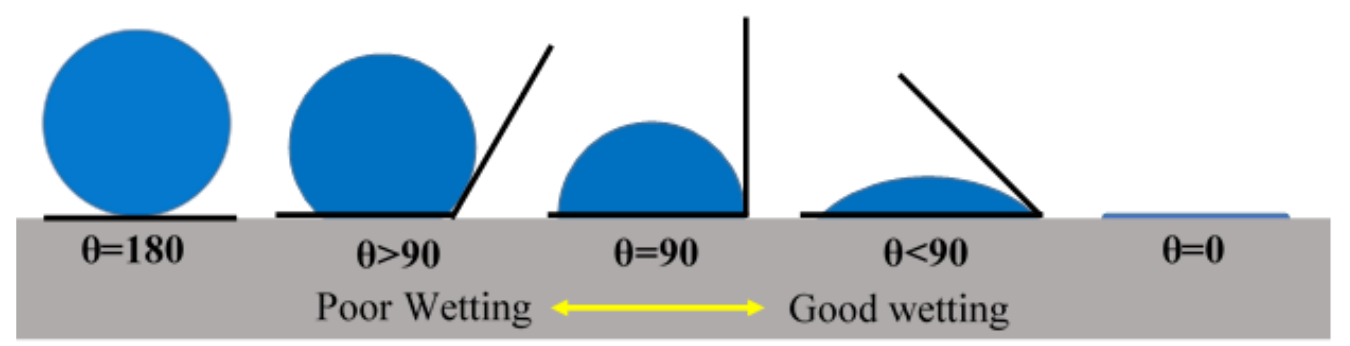

Figure-3.

Wetting degree of surfactant's liquid drop in different contact angles.

Generally, reduction of surface or interfacial tension is also known as the most important properties of surfactants in an emulsion. Basically, in a liquid the surface molecules are more energized than the interior molecules. A good surfactant must produce a good wetting efficiency with a desirable contact angle and surface tension. Furthermore, the wetting property of a surfactant indicates the ability of a liquid to cover the solid surface. Whereas, the degree wettability of a surfactant is specified by a balance between adhesive and cohesive forces. The force between a liquid and a solid that allow the liquid drop to spread across the surface is called adhesive force. While, cohesive force is a force that prevents the liquid drop to make contact with the solid surface and cause the drop to ball up [21]. Lee, et al. [22], studied the contact angle of two different biosurfactant and he found that both surfactant systems indicated a contact angle of less than $39^{\circ}$. A contact angle of $\theta=180^{\circ}$ means that the liquid makes no contact with the solid substrate and is called non-wetting. However, when $180^{\circ}>\theta>90^{\circ}$ in this case these surfactants have hydrophobic feature and tend to stabilize W/O emulsions and may refer to poor wetting. On the other hand, when $0^{\circ}<\theta<90^{\circ}$ indicates that wetting of the surface is favorable and these surfactants show hydrophilic characteristic which are suitable for $\mathrm{O} / \mathrm{W}$ emulsions. Whereas, when the $\theta=0^{\circ}$ the liquid spreads on the surface of substrate and a complete wetting occurs [8, 15, 20, 23]. Figure 3 shows the wetting ability of surfactants with various contact angles on the substrate.

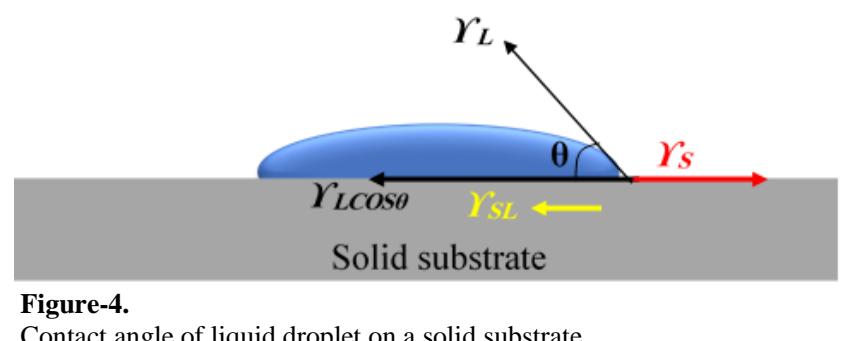

The contact angle of a liquid is the physical measurement of three interfacial tension values as presented in Young's equation Equation1 [24, 25]. Figure 4 represents these interfacial tensions.

$$
r_{S}=r L \cos \theta+r_{S} L
$$

Where, $\theta$ is the contact angle, $\Upsilon_{s}$ is surface tension of solid, $\Upsilon L$ is surface tension of liquid and $\Upsilon_{s L}$ is interfacial tension of liquid and solid of solid-liquid interface free energy.

\subsection{Foaming Property of Biosurfactants}

Foams are colloidal systems containing a gas as the dispersed phase and liquid or solid as continuous phase. Generally, foams have two different structures which may occur in spherical bubbles and foams containing polyhedral cells. In addition, their structure has tendency to change under the gravity, when the foams are in liquid form they obtain a spherical shape, however their structure changes to a polyhedral form when they get dry [26-28], as shown in Figure 5. The foaming characteristic of surfactant solutions is also known as an important property which can define the foam volume of a liquid.

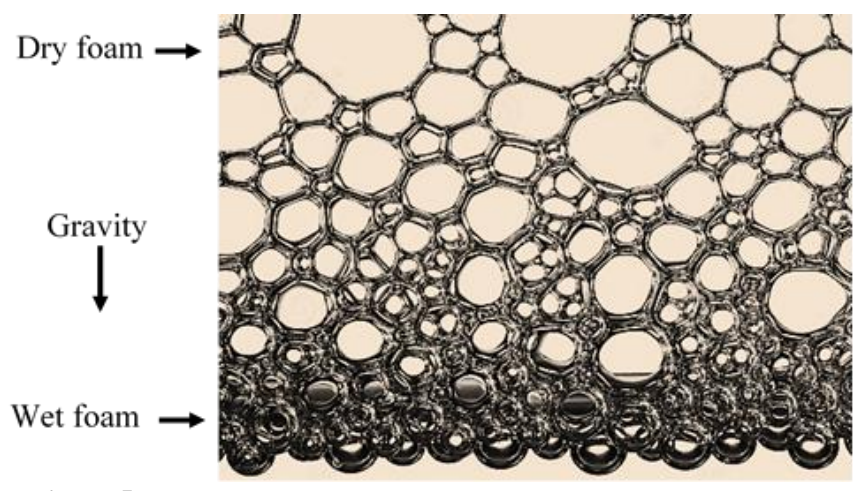

Figure-5.

Foam structure in the form of dry and wet and its variation under the gravity. 
Thermodynamically, foams are unstable systems while they can be stabilized by surfactants. In fact, the foamability and stability of foams increase with increasing the surfactant concentration up to the critical micelle concentration (CMC). However, above the CMC there is not any significant effect. The stability of foam decreases with the presence of oils and other particles [29]. Jian, et al. [30] investigated the foamability and foam stability of a biosurfactant named tea saponin (TS). Through their research, they found that TS were able to produce foam but its foamability and stability increased when it is mixed with the synthetic surfactant.

\subsection{Antimicrobial property of biosurfactants}

Biosurfactants have been widely used as antimicrobial agent in food and medical industries. Basically, the naturally occurring glycolipids and lipopeptides in biosurfactants increase their antimicrobial feature [2, 12, 17, 31].Doheim [32] and Gomaa [33] studied the antimicrobial activity of biosurfactant and they claimed that biosurfactant showed a good antimicrobial activity against different bacterial and fungal species. Besides, it has been reported that the antimicrobial activity of biosurfactants make them a promising compound for therapeutic application [34-37].

\section{Conclusions}

Understanding the application of biosurfactant in emulsification, wetting, foaming and bacterial removal, challenges that more biosurfactants need to be investigated. This review found that the nature of biosurfactants makes them a promising molecule due to their availability, biodegradability, low toxicity, and renewability. Therefore, these compounds can be used in food, cosmetic, medicine and many other products related directly to human's safety.

\section{References}

[1] B. Bhattacharya, T. K. Ghosh, and N. Das, "Application of bio-surfactants in cosmetics and pharmaceutical industry," Scholars Academic Journal of Pharmacy, vol. 6, pp. 149-157, 2017.

[2] C. N. Mulligan, "Recent advances in the environmental applications of biosurfactants, Curr," Opin. Colloid Interface Science, vol. 14, pp. 372-378, 2009. Available at: https://doi.org/10.1016/j.cocis.2009.06.005.

[3] A. Shah, S. Shahzad, A. Munir, M. N. Nadagouda, G. S. Khan, D. F. Shams, D. D. Dionysiou, and U. A. Rana, "Micelles as soil and water decontamination agents," Chemical Reviews, vol. 116, pp. 6042-6074, 2016. Available at: https://doi.org/10.1021/acs.chemrev.6b00132.

[4] C. F. Albuquerque, C. L. Luna-Finkler, R. D. Rufino, J. M. Luna, C. T. de Menezes, V. A. Santos, and L. A. Sarubbo, "Evaluation of biosurfactants for removal of heavy metal ions from aqueous effluent using flotation techniques," International Review of Chemical Engineering, vol. 4, pp. 156-161, 2012.

[5] J. Luna, R. Rufino, and L. Sarubbo, "Biosurfactant from Candida sphaerica UCP0995 exhibiting heavy metal remediation properties," Process Safety and Environmental Protection, vol. 102, pp. 558-566, 2016. Available at: https://doi.org/10.1016/j.psep.2016.05.010.

[6] J. Tang, J. He, T. Liu, and X. Xin, "Removal of heavy metals with sequential sludge washing techniques using saponin: optimization conditions, kinetics, removal effectiveness, binding intensity, mobility and mechanism," RSC Advances, vol. 7, pp. 33385-33401, 2017. Available at: https://doi.org/10.1039/c7ra04284a.

[7] H. Salehizadeh and S. Mohammadizad, "Microbial enhanced oil recovery using biosurfactant pro- duced by Alcaligenes faecalis," October, vol. 7, pp. 216-223, 2009.

[8] Y. Al-Wahaibi, S. Joshi, S. Al-Bahry, A. Elshafie, A. Al-Bemani, and B. Shibulal, "Biosurfactant production by bacillus subtilis B30 and its application in enhancing oil recovery," Colloids Surfaces B Biointerfaces, vol. 114, pp. 324-333, 2014. Available at: https://doi.org/10.1016/j.colsurfb.2013.09.022.

[9] P. L. Fernandes, E. M. Rodrigues, F. R. Paiva, B. A. L. Ayupe, M. J. McInerney, and R. Tótola, "Biosurfactant, solvents and polymer production by Bacillus subtilis RI4914 and their application for enhanced oil recovery," Fuel, vol. 180, pp. 551-557, 2016. Available at: https://doi.org/10.1016/j.fuel.2016.04.080

[10] Q. F. Cui, S. S. Sun, Y. J. Luo, L. Yu, and Z. Z. Zhang, "Comparison of in-situ and ex-situ microbial enhanced oil recovery by strain pseudomonas aeruginosa WJ-1 in laboratory sand-pack columns," Petroleum Science and Technology, vol. 35, pp. 20442050, 2017. Available at: https://doi.org/10.1080/10916466.2017.1380042.

[11] M. Kitagawa, S. Michiko, S. Yamamoto, and M. Fukuoka, "Biosurfactant-containing skin care cosmetic and skin roughness improving agent," 2011.

[12] E. J. Gudiña, V. Rangarajan, R. Sen, and L. R. Rodrigues, "Potential therapeutic applications of biosurfactants," Trends in Pharmacological Sciences, vol. 34, pp. 667-675, 2013. Available at: https://doi.org/10.1016/j.tips.2013.10.002.

[13] M. Nitschke and S. G. V. A. O. Costa, "Biosurfactants in food industry," Trends Food Sci. Technol, vol. 18, pp. 252-259, 2007.

[14] M. Pacwa-Płociniczak, G. A. Płaza, Z. Piotrowska-Seget, and S. S. Cameotra, "Environmental applications of biosurfactants: Recent advances," International Journal of Molecular Sciences, vol. 12, pp. 633-654, 2011. Available at: https://doi.org/10.3390/ijms12010633.

[15] R. Pichot, F. Spyropoulos, and I. Norton, "O/W emulsions stabilised by both low molecular weight surfactants and colloidal particles: The effect of surfactant type and concentration," Journal of Colloid and Interface Science, vol. 352, pp. 128-135, 2010. Available at: https://doi.org/10.1016/j.jcis.2010.08.021.

[16] T. F. Tadros, "Emulsion formation, stability , and rheology," pp. 1-75, 2013.

[17] E. Mendes Lopes, "Emulsification properties of bioemulsifiers produced by wild-type and mutant bradyrhizobium elkanii strains," Journal of Bioremediation and Biodegradation- Open Access, vol. 5, 2014. Available at: https://doi.org/10.4172/21556199.1000245.

[18] K. A. Peele, V. R. T. Ch, and V. P. Kodali, "Emulsifying activity of a biosurfactant produced by a marine bacterium," vol. 6, pp. 1-6., 2016. Available at: https://doi.org/10.1007/s13205-016-0494-7 
[19] J. C. Camacho-Chab, J. Guézennec, M. J. Chan-Bacab, E. Ríos-Leal, C. Sinquin, R. Muñiz-Salazar, S. d. C. D. Rosa-García, M. Reyes-Estebanez, and B. O. Ortega-Morales, "Emulsifying activity and stability of a non-toxic bioemulsifier synthesized by Microbacterium sp. MC3B-10," International Journal of Molecular Sciences, vol. 14, pp. 18959-18972., 2013. Available at: https://doi.org/10.3390/ijms140918959.

[20] T. F. Tadros, "Applied surfactants: Principles and applications," 2005.

[21] S. Rattle, O. Hofmann, C. P. Price, L. J. Kricka, and D. Wild, Lab-on-a-chip, micro- and nanoscale immunoassay systems, and microarrays, 4th ed., 2013.

[22] S. M. Lee, J. Y. Lee, H. P. Yu, and J. C. Lim, "Synthesis of environment friendly biosurfactants and characterization of interfacial properties for cosmetic and household products formulations," Colloids Surfaces A Physicochem. Eng. Asp, vol. 536, pp. 224-233, 2017. Available at: https://doi.org/10.1016/j.colsurfa.2017.05.001.

[23] Z. Liu, Z. Li, H. Zhong, G. Zeng, Y. Liang, M. Chen, Z. Wu, Y. Zhou, M. Yu, and B. Shao, "Recent advances in the environmental applications of biosurfactant saponins: A review," Journal of Environmental Chemical Engineering, vol. 5, pp. 6030-6038, 2017. Available at: https://doi.org/10.1016/j.jece.2017.11.021.

[24] K. Szymczyk and A. Zdziennicka, "Adsorption and wetting properties of cationic, anionic and nonionic surfactants in the glass-aqueous solution of surfactant-air system," Mater. Chem. Phys, vol. 162, pp. 166-176, 2015. Available at: https://doi.org/10.1016/j.matchemphys.2015.05.054.

[25] Y. Zhu, M. L. Free, R. Woollam, and W. Durnie, "A review of surfactants as corrosion inhibitors and associated modeling," Progress in Materials Science - Journal, vol. 90, pp. 159-223, 2017. Available at: https://doi.org/10.1016/j.pmatsci.2017.07.006.

[26] W. Drenckhan and S. Hutzler, "Structure and energy of liquid foams," Advances in Colloid and Interface Science, vol. 224, pp. 1-16, 2015. Available at: https://doi.org/10.1016/j.cis.2015.05.004.

[27] W. Drenckhan and D. Langevin, "Monodisperse foams in one to three dimensions, Curr," Opin. Colloid Interface Sci, vol. 15, pp. 341-358, 2010. Available at: https://doi.org/10.1016/j.cocis.2010.06.002.

[28] D. Beneventi, B. Carre, and A. Gandini, "Role of surfactant structure on surface and foaming properties," Colloids Surfaces A Physicochem. Eng. Asp, vol. 189, pp. 65-73, 2001. Available at: https://doi.org/10.1016/s0927-7757(01)00602-1.

[29] A. B. Osama Al, "Foamability and foam stability of several surfactants solutions: The role of screening and flooding," Journal of Petroleum \& Environmental Biotechnology Open, vol. 6, pp. 1-6, 2015. Available at: https://doi.org/10.4172/21577463.1000227.

[30] H. L. Jian, X. X. Liao, L. W. Zhu, W. M. Zhang, and J. X. Jiang, "Synergism and foaming properties in binary mixtures of a biosurfactant derived from camellia oleifera Abel and synthetic surfactants," Journal of Colloid and Interface Science - Journal - Elsevier, vol. 359, pp. 487-492, 2011. Available at: https://doi.org/10.1016/j.jcis.2011.04.038.

[31] T. Ndlovu, M. Rautenbach, J. A. Vosloo, S. Khan, and W. Khan, "Characterisation and antimicrobial activity of biosurfactant extracts produced by bacillus amyloliquefaciens and pseudomonas aeruginosa isolated from a wastewater treatment plant," AMB Express, vol. 7, pp. 1-19, 2017. Available at: https://doi.org/10.1186/s13568-017-0363-8.

[32] M. M. Doheim, "Selection of Pseudomonas aeruginosa for biosurfactant production and studies of its antimicrobial activity," Egyptian Journal of Petroleum - Journal - Elsevier, vol. 23, pp. 1-6, 2014. Available at: https://doi.org/10.1016/j.ejpe.2014.02.001.

[33] E. Z. Gomaa, "Antimicrobial activity of a biosurfactant produced by bacillus licheniformis strain M104 grown on whey," BRAZILIAN Arch. Biol. Technol, vol. 56, pp. 259-268, 2013. Available at: https://doi.org/10.1590/s1516-89132013000200011.

[34] P. M. G. Dineshkumar, T. J. K. Deepalakshmi, and C. G. Kumar, "Antimicrobial activities of a promising glycolipid biosurfactant from a novel marine," Staphylococcus Saprophyticus SBPS, vol. 6, pp. 1-9, 2016. Available at: https://doi.org/10.1007/s13205-016-0478-7.

[35] D. Ghribi, L. Abdelkefi-mesrati, I. Mnif, R. Kammoun, I. Ayadi, I. Saadaoui, S. Maktouf, and S. Chaabouni-ellouze, "Investigation of antimicrobial activity and statistical optimization of bacillus subtilis SPB1 biosurfactant production in solidstate fermentation," Journal of Biomedicine and Biotechnology - Hindawi, pp. 1-12, 2012. Available at: https://doi.org/10.1155/2012/373682.

[36] D. Rienzo, P. Stevenson, R. Marchant, and I. M. Banat, "Antibacterial properties of biosurfactants against selected Grampositive and -negative bacteria," FEMS Microbiol. Lett, vol. 363, pp. 1-8, 2018 . Available at: https://doi.org/10.1093/femsle/fnv224.

[37] R. D. Rufino, J. M. Luna, L. A. Sarubbo, L. R. M. Rodrigues, J. A. C. Teixeira, and G. M. Campos-takaki, "Colloids and surfaces B : Biointerfaces antimicrobial and anti-adhesive potential of a biosurfactant Rufisan produced by Candida lipolytica UCP 0988," Colloids Surfaces B Biointerfaces, vol. 84, pp. 1-5, 2011. 